This is an Accepted Manuscript of an article published by Taylor \& Francis in Research on Language and Social Interaction 2014, 47 (1), pp. 49-68. Available online:https://www.tandfonline.com/doi/abs/10.1080/08351813.2014.871805

\title{
Using formulations and gaze to encourage parents to talk about their and their children's health and well-being
}

Sanni Tiitinen \& Johanna Ruusuvuori

School of Social Sciences and Humanities, University of Tampere, Finland

This research was supported by the Finnish Doctoral Program of Social Sciences (Sovako). The data was collected in the course of a research project that has had two grants from the Juho Vainio Foundation. We would like to thank Riikka Homanen,Pirjo Lindfors and Aku Kallio for their collaboration in the research project, and Elina Weiste for her valuable comments on the analyses. We also thank participants in the seminars and datasessions in University of Tampere and Helsinki during 2011-2013. 


\begin{abstract}
In preventive health care settings, professionals need to encourage clients to talk about their problems before they become critical. We use multimodal conversation analysis to demonstrate how public health nurses encourage parents to elaborate on their problems in a sample of preventive maternity and child health $(\mathrm{MCH})$ clinics in Finland. The nurses topicalize the problem-relevant aspects of the parents' problem-indicative talk by issuing a formulation of what the parent has just said (that is, by re-describing it in problem-related terms). This verbal practice is synchronised with a visual one - the nurse issues the formulation, receives the parent's response, and then gazes directly at them: this has the effect of prompting the parent to take up the problem and talk about it. We discuss the findings in relation to the institutional tasks in $\mathrm{MCH}$ care and to the role of gaze in constituting actions, such as formulations. Data in Finnish and English translation.
\end{abstract}




\section{Introduction}

Professionals use various interactional practices to elicit and manage clients' talk about their problems in health care settings. An array of previous research has illustrated how different types of questions serve the tasks of getting information about the client's problem and building the relationship between the client and the medical professional (Boyd \& Heritage, 2006; Heritage, 2010; Stivers, 2007). For example, follow-up questions about the client's situation have been demonstrated to help the professional to design more suitable advice for the client in encounters between health visitors and mothers (Heritage \& Sefi, 1992). Practices of encouraging clients to talk about their problems are especially relevant in routine preventive health care settings in which the consultation is not fundamentally structured around solving a specific problem. As in preventive health care in general, the purpose of Finnish maternity and child health (MCH) clinics is to identify and prevent possible social and developmental problems in advance. The encounters in $\mathrm{MCH}$ clinics are structured around discussing current issues in the family's everyday life and routine monitoring of the pregnancy and the development of the child. In this article, we show how public health nurses encourage parents to say more about their problems by topicalizing their problem descriptions using formulations, and by using gaze in a certain way.

In their seminal papers, Heritage and Watson $(1979,1980)$ define formulations as utterances which present a version, either a summary or a natural implication, of what the previous speaker has said, and thus demonstrate an understanding of it. Formulating is a frequent practice, especially in institutional interaction and some core activities of institutions are typically managed through formulating (Drew, 2003). Heritage and Watson (1979; 1980, pp. 258) state that formulations can be treated as proliferating more talk on the topic in hand or as suggesting its closure, and there is nothing intrinsically different between these two kinds of orientation. More recently, studies on 
formulations in health care encounters have given evidence on formulations as both topicalizing and closing. Beach and Dixson (2001) have suggested that in health appraisal interviews, formulations are a part of a distinct pattern of interaction, a "formulations cycle", in which the interviewer's formulation and the patient's confirmation are typically followed by the topic shift by the interviewer. On the other hand, in child counselling encounters, formulations preserve the selected aspects of the client's utterance as the topic of talk and thus typically occasion more talk on the topic by either the counsellor or the client (Hutchby, 2005, pp. 316-317). We suggest that in the context of $\mathrm{MCH}$ clinic encounters a particular way of designing formulations in relation to clients' previous problem-indicative turn serves to generate more talk rather than suggest closure to the sequence.

In addition to analysing the lexical and sequential properties of formulations, we investigate the effect of a non-verbal element, the nurse's gaze direction, on the association between formulations and courses of action. Previous studies have demonstrated that gazing at the intended recipient at turn transition is an efficient turn allocation device in multiparty conversations (Lerner, 2003; Sacks, Schegloff \& Jefferson, 1974; Tiitinen \& Ruusuvuori, 2012). Further, gazing at the recipient is one of the resources used to mobilize a response in interaction (Stivers \& Rossano, 2010) as well as to display engagement in receiving the upcoming talk (Goodwin, 1979, 1980, 1981; Heath, 1984; Robinson, 1998; Ruusuvuori, 2001). In addition, a shift in gaze and body posture away from the other participant towards a computer or papers, for example, at turn transition displays disengagement from the reception of the upcoming talk and orientation towards another activity (Ruusuvuori, 2001; see also Schegloff, 1998; Robinson \& Stivers, 2001; Mondada, 2006). Similarly, Rossano (2012, pp. 308; 2013, pp. 319-322) has shown that if both participants withdraw from gazing at each other at a possible sequence completion, the sequence will usually end; whereas otherwise it typically gets expanded. Moreover, Rossano (2012, pp. 309) has 
demonstrated that gaze is organized in relation to "participants' understanding of where they are in a course of action". We suggest that the nurse's gaze direction is relevant with regard to the association between formulating and constituting the action of dealing with the problems in $\mathrm{MCH}$ clinics.

In the following, we first describe the setting of MCH clinics, the data, and the focus of analysis. We then illustrate the specific features of the practice of topicalizing by formulating by comparing it to 1) formulating that steers the conversation towards closing the talk about problems and 2) topicalizing problem talk with follow-up questions. Thereafter, we demonstrate that the practice is not limited to a certain sequential place or the design or topic of the problem-indicative utterance as it can be used in different stages of dealing with the problem and after both explicit and implicit problem-indicative utterances. To finish with, we discuss our findings in relation to the institutional tasks in $\mathrm{MCH}$ care, and the contribution of the findings to existing knowledge on formulations, and on the role of non-lexical elements (especially gaze) in constituting the orientation of the participants to the continuing or closing the courses of action.

\section{Maternity and child health clinics as a preventive service}

In Finland, almost all families with children regularly attend the public $\mathrm{MCH}$ clinics from the start of pregnancy until the child is 6 years old. Nationwide regulations assign each family a right to attend certain number of encounters during pregnancy and following the childbirth. The encounters are voluntary, free-of-charge, regular routine check-ups. Typically, they begin with a discussion about current issues (how the mother/baby/family has been doing) which is followed by a routine physical examination of the mother (e.g., taking blood pressure, listening to the heart beat of the foetus) or the child (e.g., measuring weight and height, testing age related development). The first encounter during pregnancy is an exception as it is structured around going through and 
recording the background information about expectant parents. At the end of each encounter, there is usually some time for discussion and also for scheduling the next appointment.

As a preventive service which reaches almost all expectant parents and families with children, $\mathrm{MCH}$ clinics have a major role in detecting and managing various concerns that parents have. The present MCH policy in Finland is that professionals should be able to spot potential problems concerning for example, the progression of the pregnancy, child development, upbringing, parents' mood, and social relationships at an early stage (MSAH, 2004). Previous research has shown that although public health nurses in Finnish child health clinics are relatively competent in detecting the factors that may hinder the child's healthy development, discussing these issues together with parents is challenging (Puura et al., 2001). This difficulty may arise from institutional factors. Institutions of preventive health care share the problem of fulfilling not only a supportive but also a controlling function in society (Bredmar\& Linell, 1999; see also Heritage \& Lindström, 1998). Bringing up problems concerning childcare and family issues at the clinic may thus be interpreted as breaching the line of public and private, as intervening with the families' private matters and undermining the parents' competence in managing routine family responsibilities.

\section{Data and the focus of the analysis}

The data for this study is drawn from a larger database of 143 encounters in MCH clinics, collected in one middle-sized town in Finland between 2006 and 2008. In this study, we use 30 video-recorded encounters, 14 of which were recorded during pregnancy and 16 after the baby was born. In these 30 encounters, the parties present are the nurse, either both of the parents or the mother only, and in the 16 cases the baby as well. On some occasions, there is also a medical or nursing student or an older sibling of the baby present, but they do not take part in the conversations analysed here. The encounters were video-recorded in four different clinics with nine different 
nurses and 28 client families. ${ }^{1}$ The participants offered their informed consent to be video-recorded for the purposes of the research project. The ethical board of the city providing for the clinics gave the permission to collect the data.

Using conversation analysis with a multimodal focus (Stivers \& Sidnell, 2005), we analyse the sequences of interaction in which the parents indicate that they may have a current problem. The talk about problems is initiated in several ways at $\mathrm{MCH}$ clinics. The parents may request advice or bring up a problem related to the on-going activity (see Nishizaka, 2010), but in our data, talk about problems is most frequently initiated by the nurses. We focus on these cases $(n=96)$. We have also included the cases $(n=31)$ in which the discussion about the problem in the former 96 cases is reopened by either the nurse or the parents later in the same encounter. In its most straightforward course, the sequence of steps that interests us is: (1) the nurse's initial inquiry or problem-indicative description, (2) the parents' problem-indicative answer, (3) some follow-up question(s)/topicalizing utterance(s) and/or (4) elaboration on the problem by the parents and finally (5) a solution for the problem. (A similar course of action is described by Heritage and Sefi (1992, pp. 377-389) for the health visitor-mother -interaction, which they call "step-by-step movement into advice giving”.) We focus on the nurses' formulations $(n=32)$ that follow the parents' problem description; that is, either the initial problem-indicative answer, step 2, or elaboration on the problem, step 4. Specifically, we are interested in the formulations that are used to topicalize parents' problemindicative turns $(\mathrm{n}=15)$.

Formulations may be realized in varying linguistic forms (see Drew, 2003, pp. 306-307). They may resemble candidate understandings (Antaki, 2012, pp. 534) or declarative questions (Deppermann \& Spranz-Fogasy, 2011, pp. 115) but the action of formulating we analyse in this article demonstrates understanding rather than checks it. In our data, formulations often include 
particles that show that they are inferences from previous conversation, such as sitte "then" at the end of the turn or nii (joo) että "so" at the beginning of the turn (see Sorjonen, 2001, pp. 48-49; VISK $§ 1200, \S 1207-1208)$. Although designed to be mere summaries or logical implications, formulations always delete some information and preserve other in the previous talk, transforming the information selected for preservation (Antaki, 2008, pp. 31-33; Heritage \& Watson, 1979, pp. 129). Moreover, formulations form an adjacency-pair with the second pair part called the decision that is, confirmation or disconfirmation (Heritage \& Watson, 1979, 1980). We also analyse these second pair parts by the parents.

\section{The specific features of topicalizing by formulating as compared to other formulations and ways of topicalizing problem talk}

We begin this section by presenting a case in which the nurse topicalizes the mother's problem description by formulating it. We compare it, on the one hand, to a case in which the nurse uses a formulation to suggest closing the talk about the problem, and on the other hand, to different way of topicalizing, namely by follow up questions.

Extract 1 presents a typical case in which the nurse uses a formulation to encourage the mother to elaborate on her problem description. The nurse has written down some background information about the mother and her partner. At the beginning of the encounter, the mother has eaten a grapefruit. The nurse's turns in focus are at lines 4 and 6 .

Extract 1 (the first encounter during pregnancy) ${ }^{2}$

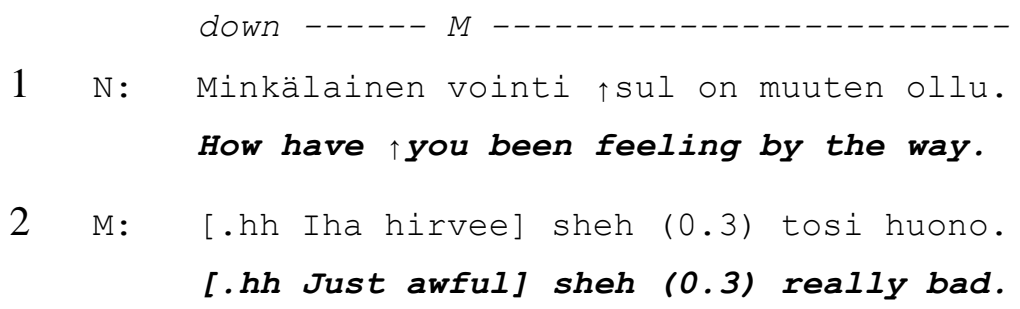


$3 \quad \mathrm{~N}: \quad[$ turns to $\mathrm{M}$

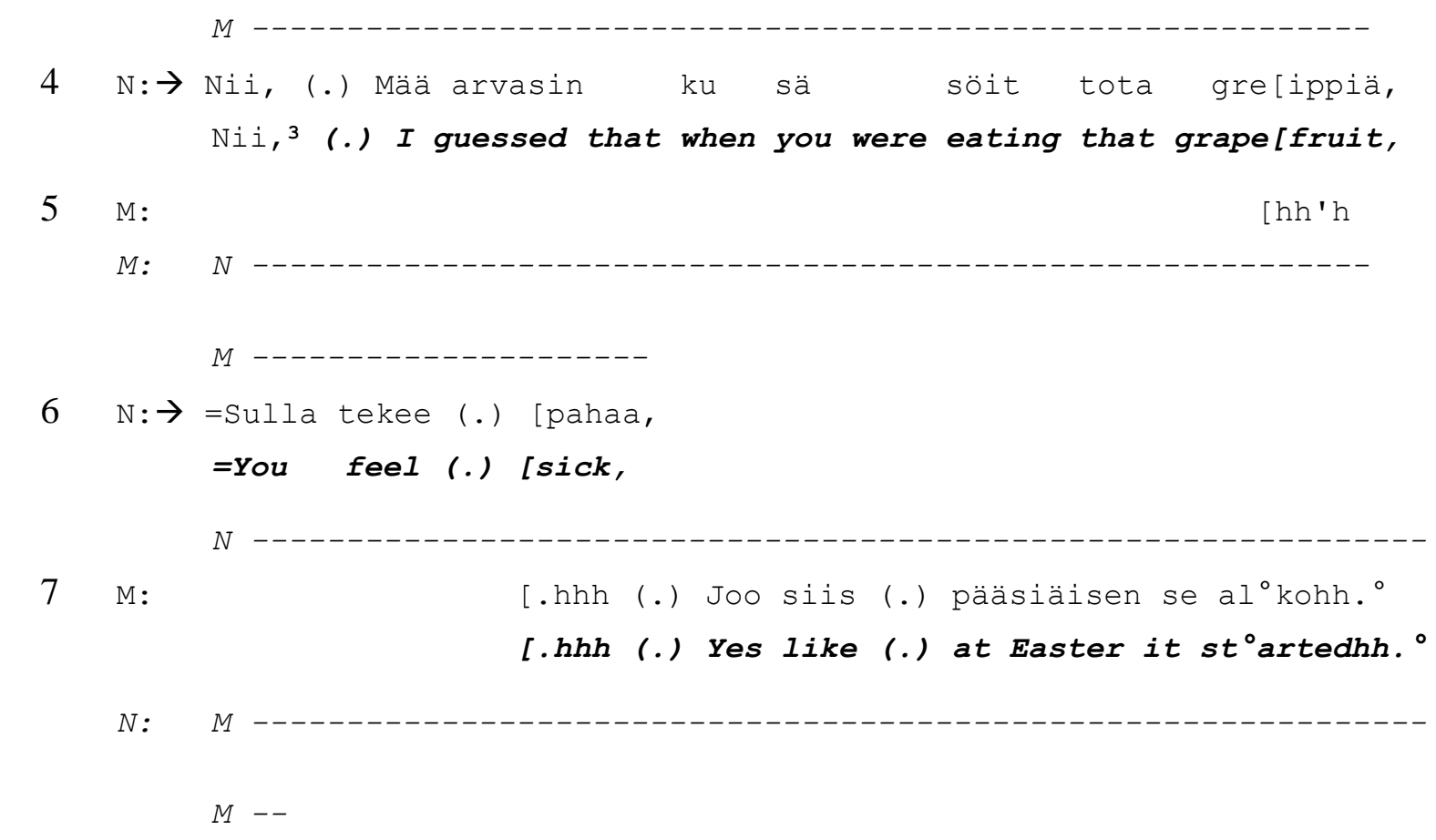

$8 \quad \mathrm{~N}: \quad \mathrm{Ni}$,

$M: \quad N--$

9 M: \#Oikeen sillai että\# (0.9) on ollu kyllä että (.)

\#Really it has been like\# (0.9) it has indeed been that (.)

10

en muista että pojasta olis ollu ihan tällasta

I don't remember having ((it)) quite like this when $I$ was expecting

11

12

et >voi tietysti< olla et se oli (.) erilaista

my son so >it might be of course< that it was (.) different

k [ e ollu sitä lasta siinä ja ny ku pitäs

w [hen there was not the child the[re and now when you should

$13 \mathrm{~N}: \quad[\mathrm{Mm}: \mathbf{2} \quad[\mathrm{Mm}:$.

$14 \mathrm{M}$ : suoriutua .hh $\downarrow$ kylä mää oon melko toimintakyvytön kotona ( (...))

cope .hh $\downarrow I^{\prime}$ ve really been quite unable to function at home ((..))

At line 1, the nurse asks how the mother has been feeling. The word "vointi" in the question in Finnish refers mainly to physical condition but may also include psycho-social wellbeing. The mother's answer "just awful sheh (0.3) really bad" explicitly introduces a problematic situation. At line 4, the nurse first receives the mother's problem-indicative answer with a response token "nii" which in this context indicates that the nurse is treating the knowledge on the mother's feelings as shared, this 
way also claiming recognition of the situation described (Sorjonen, 2001, pp. 164). The nurse's reference to the mother eating grapefruit demonstrates understanding of her problematic situation, since eating a grapefruit is interpreted as a sign of pregnancy sickness. After these affiliative utterances, the nurse rushes forward to formulate the mother's problem-indicative response, "you feel sick". The formulation further addresses the problem-relevant aspect of the situation, since feeling sick is a negative somatic condition. Although the affiliative utterances before the formulation recognize the problem, as a first pair-part it is the formulation that makes further talk about the problem explicitly relevant. The first specific feature of the practice of topicalizing by formulating is that the nurse addresses the problem by focusing on the problem-relevant aspect of the situation in her formulation. The problem-focus may also be strengthened by a verbal or non-verbal expression of affiliation with the client.

The second specific feature of topicalizing by formulating is the nurse's orientation towards receiving more talk about the problem by leaving space and gazing at the parents. At the closure of her formulation (line 6), the nurse gazes at the mother and remains silent. At line 7, the mother first confirms the formulation and continues to give more details of the problem in the same intonation unit. The first possible completion of the formulation-decision pair would be after the mother's confirmation, and at this point, the nurse continues to gaze at the mother. The mother's response "yes like at Easter it started" begins a multi-part telling (Schegloff, 2007, pp. 215-216) as she refers to the starting point of her awful condition, and she also displays the shift non-verbally by changing her position from leaning against the table to lying back on her chair (see Robinson \& Stivers, 2001). The nurse's continuous gaze at the mother displays her orientation to the course of action not being complete (Rossano, 2012) and her engagement in receiving more talk about the problem (Goodwin, 1981; Ruusuvuori, 2001). 
These two specific features - focusing on the problem-relevant aspect of the parent's preceding problem-indicative utterance, and orienting to receiving more talk about the problem by leaving space after the formulation and by gazing at the parents at turn transitions following the formulation and parents' confirming response - form the practice analysed in this article. We will refer to them as for brevity's sake as topicalizing by formulating and gaze.

\section{Topicalizing versus closing.}

Now for a contrast: The following extract highlights the importance of those two features by showing how a nurse uses a formulation not to topicalize the problem, but, on the contrary, to close the problem down. Extract 2 below is taken from the same first encounter as Extract 1, and it shows the end of the discussion about the mother's severe pregnancy sickness. Before the beginning of the extract, the nurse has already given some information and advice during the conversation and the mother has given increasingly extreme descriptions about her problematic situation. At the beginning of the extract, the nurse gives information about vitamin B which could potentially help with nausea. The formulation in focus is at line 18 .

\section{Extract 2 (the first encounter during pregnancy)}

1 N: Mutta (.) sitä (0.2) sitä (.) sitä nyt $\downarrow$ voi kokeilla. ${ }^{\circ}$

But (.) that (0.2) that (.) that now $\downarrow$ you could $t^{\circ}$ ry. ${ }^{\circ}$

$2 \quad(1.4)$

$3 \mathrm{M}$ : \#Joo no kyllä mä apteekissaki oon käyny >ky\#sym[ässä

\#Yes well actually $I^{\prime}$ ve been to pharmacists' >to as [k

$4 \mathrm{~N}:$

$[\mathrm{Mmm}:$ : ,

$5 \mathrm{M}: \quad$ (eikö)< emitään mit (h) ään $\mathrm{p}(\mathrm{h})$ oppakonstia@ e $\mathrm{t}_{\text {.hh }}$ (.)

(isn't there)< eany an(h)y $r(h)$ emedye that .hhh (.)

$6 \mathrm{~N}:$

$[\uparrow \mathrm{Mmm}$,

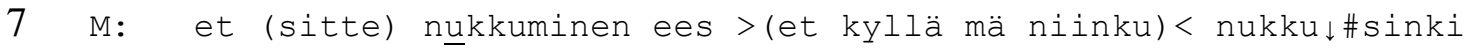

that (then) even sleeping $>$ ( $I$ would indeed you know $)<$ also sleep 
paljon\# ${ }^{\circ}$ [että tota ${ }^{\circ}$ se [on niinku semmone et sit ku s- siihen

a lot\# ${ }^{\circ}$ [so like ${ }^{\circ}$ it [is like so that when you get to t- that

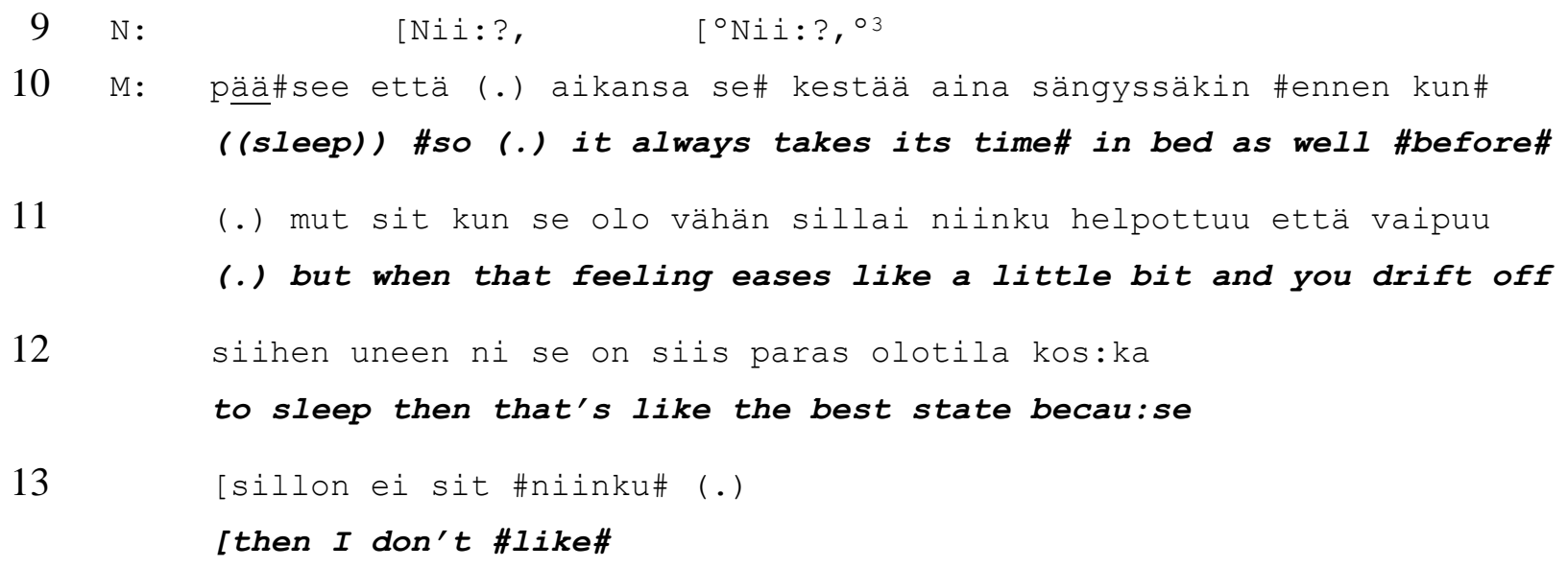

The mother's response at lines 3 and 5 displays resistance to the delivery of the information by the nurse as it indicates that the mother has already known the information (Heritage\& Sefi, 1992, pp. 402-409). After responding to the information-giving, the mother continues the problem 
description by describing a new aspect of her condition. The description is extreme - the mother suggests that the only time when she does not feel sick is when she is sleeping.

Our interest is in line 18, where the nurse picks up this last-mentioned aspect of the mother's description and formulates the negatively designed statement in positive terms "then you feel rather good". She also initiates laughter after the formulation. As the mother, the teller of the problem, is not laughing at this point, the nurse's laughter may indicate some resistance to receiving the problem description and thus suggests closing the talk about the problem (Jefferson, 1984, 1988). The point to stress is the contrast with the encouraging use of formulation that we saw in Extract 1 - here, on the contrary, both the semantic content of the formulation and the non-verbal way of producing it with laughter, display the nurse's non-problem stance towards the situation described by the mother. Displaying a non-problematic stance towards the situation indicates that it is not a problem needing to be solved, and thus, suggests closing the talk about it (see Ruusuvuori, 2005).

It is not only the formulation that does closing work, but the nurse's gaze direction and body posture, too. In Extract 1, the nurse gazed at the mother, whereas here, towards the end of the formulation, the nurse turns from the mother towards the computer screen and puts her hand on the mouse. At the first possible completion of the formulation-decision pair, after the mother has confirmed the formulation (line 19), the nurse is gazing towards the computer. Turning towards and gazing at the computer screen displays a shift in orientation from talking about the problem to entering the preliminary information about the mother at the computer (Robinson \& Stivers, 2001; Schegloff, 1998).

In overlap with the nurse's formulation, the mother continues her problem description with "but so it", but cuts off her turn and confirms the formulation at line 19. It is noteworthy though that she qualifies the temporary positive state of not feeling sick with "as you're not moving at all there 
then" that reinforces the severity of her condition. However, the nurse continues to gaze at the computer which indicates that the information in the computer is her principal object of orientation (Ruusuvuori, 2001). At line 22, she verbally initiates the shift from talking about the problem to entering the preliminary information at the computer which was already displayed non-verbally by turning to the computer.

To summarize then, what the contrast between Extrats 1 and 2 tells us. Two features are distinctive in the practice of topicalizing the parents' problem description by formulating. The first is that the nurse addresses the problem by focusing on the problem-relevant aspects of the situation in her formulation. This problem-focus may also be strengthened by a verbal or non-verbal expression of affiliation with the client. Affiliation may be observable in the nurse's responsive turns during or after the parent's problem description before the formulation, and be demonstrated non-verbally through such things as a serious face and tone of voice. Compared to an affiliative minimal response alone, a formulation makes elaboration explicitly relevant as it is a first pair part (Heritage \& Watson, 1980). Accordingly, after each of the formulations in our data, the parents take at least one turn of talk to respond. However, in every case of topicalizing by formulating and gaze the parents not only minimally confirm the formulation but offer more details about the problem. The second important feature of the practice in focus is that the nurse displays engagement in receiving the continuation of the problem description by remaining quiet after the formulation and by gazing at the parent (Goodwin, 1981; Heath, 1984; Rossano, 2012, 2013; Ruusuvuori, 2001).

\section{$\underline{\text { Formulation and gaze versus other ways of topicalizing problems }}$}

So far, we have presented the specific features of the practice of topicalizing by formulating and gaze compared to an opposite way of using formulations that is, closing the talk about the problem. Next, we illustrate that the practice of topicalizing by formulating and gaze also has 
specific features compared to other ways of topicalizing problem talk in $\mathrm{MCH}$ encounters. The following extract shows a case that is taken from a similar sequential place as Extract 1, and the problem topicalized is also similar. As Extract 1, Extract 3 is from the first encounter during the pregnancy and it begins in a similar way as Extract 1. The nurse poses an open question about the mother's condition and the mother says that she is not feeling well. Instead of formulating the problem, the nurse first checks her understanding of the mother's description with which she has overlapped and then uses alternative and polar questions to get more information about the problem. In Extract 1, the mother had an opportunity to elaborate on the symptoms she thought relevant whereas here, the nurse addresses some normal symptoms of pregnancy.

\section{Extract 3 (the first encounter during pregnancy)}

1 N: Minkälaine vointi sulla o ollu?

How have you been feeling?

2

$$
(0.6)
$$

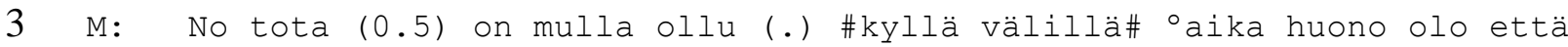

Well erm (0.5) I've felt (.) \#actually sometimes\# ${ }^{\circ}$ quite bad so

$4 \mathrm{~N}:$ Jo[0:?

Ye[s:?

M:

[ oksen [tanu $(-)^{\circ}$

[I've been [sick $(-)^{\circ}$

$6 \mathrm{~N}: \rightarrow$

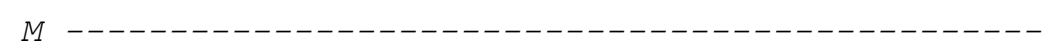

$6 \mathrm{~N}: \rightarrow$

[Pahoinvointia< oot oksentanukki iha k[unnolla,

[Nausea< You have also thrown up really p[roperly,

$M:$

$$
N
$$

7 M:

[ JoO,

[Yes, 
$9 \mathrm{~N}: \rightarrow$.hh Onks se aamupahoinvointia päiväpahoinvointia iltapahoinvointia, .hh Is it morning sickness day sickness evening sickness, $M: \quad N$

$11 \mathrm{M}$ : No (0.9) no nyt o ollu \#il\#tapahoinv\#ointia\# mut jossai Well (0.9) well now it has been \#eve\#ning s\#ickness\# but at some $N$ : $N$

12 M: vaiheessa (mä olin) kyllä okoko ajan (1.2) paha (.) olo point (I felt) actually all the time (1.2) nauseous $N: \quad M$

$N-----------------$

$13 \mathrm{M}:$ (.) jotenki.․ .HHHRK

(.) somehow. ${ }^{\circ}$.HHHRK

$N: \quad M$

M

$14 \mathrm{~N}: \rightarrow$.hh Entäs tuota niin (0.3) niin niin (1.2) onko mitään viiltelyjä .hh How about like (0.3) like like (1.2) has there been any stabbing ( (pain))

$M: \quad N$

$M$

$15 \mathrm{~N}: \rightarrow$ ollu alavatsalla tai kipuja?, on the lower abdomen or pain?, $M: \quad N$

$16(0.6)$ ( ( $N$ and $M$ gaze at each other; $M$ shakes her head)) $N--$

$17 \quad M: \quad E[: i$. $N[: 0$. 


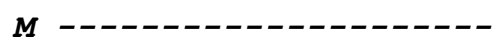

$18 \mathrm{~N}: \rightarrow \quad[>$ Entäs $<$ verenvuotoo,

[>How about< bleeding,

$M: \quad N$

19

(0.4) ( $N$ and $M$ gaze at each other; $M$ moves her head up))

up on the slant

$N$

$20 M$

.mt .h No (.) joskus (.) joulukuus ${ }^{\circ}$ sa mulla oli yhtenä päivänä

.mt .h Well (.) sometime (.) in Decem ${ }^{\circ}$ ber I had on one day

$N: \quad M$

$N$

21

M: ihan vähän mutta ei [nyt. ${ }^{\circ}$

just a little but not [now.

$N$ :

[ J०O: : ?,

[Yes: :?,

23

(.)

M

No ne on ihan kaikki [(0.3) normaaleita oireiª. ${ }^{\circ}$

Well all those are [(0.3) normal symp ${ }^{\circ}$ toms. ${ }^{\circ}$

$M:$

$N$

$25 \mathrm{M}$ :

$[k r h-k r h$.

$26 \quad($.

$27 \mathrm{~N}$ : Ja rinnat tulee araks.

And the breasts become sore.

$28 \quad(0.2)$

29 M: Jo०.

Yes.

$30 \mathrm{~N}$ : .hhh Eli nää kaikki liittyy tähän raskautee ja ((..))

.hhh so all these are related to this pregnancy and $((.)$.

Compared to the mother's problem-indicative answer in Extract 1, here the mother's answer at lines 3 and 5 is not as extreme but it still explicitly indicates that the mother is feeling sick. Her 
utterance at line 3 ends with the conjunction "että" (literally "that", translated here "so"). In Finnish, "että" in this kind of a turn-final position enables two possible interpretations: the conjunction may invite the nurse to conclude what the description means or it may serve as a stepping stone for the mother to elaborate on the topic depending on the nurse's way of receiving the utterance (Koivisto, 2011, pp. 186-190; for a comparison with other Finnish turn-final conjunctions see Koivisto, 2012). As the nurse receives the description with a continuer "joo”, "yes" the mother begins to elaborate with "I've been sick (-)". However, at the same time the nurse rushes into offering a formulation of the problem description "nausea" (line 6) and ends up talking in overlap with the mother. In consequence the mother stops her elaborative utterance. The nurse rushes into a declarative question "you have also thrown up really properly" which is an understanding check for the part of the mother's description that was uttered in overlap. The mother confirms this with a minimal response "joo", “yes” (Sorjonen, 2001).

At line 9, after the mother's confirmation, the nurse starts to ask follow-up questions about the mother's condition as in medical history-taking series at general practice consultations (Boyd \& Heritage, 2006; Stivers, 2007). First, she asks about the time of the day when the mother is feeling sick (line 9) and right after the mother's answer, she poses the next question about another symptom, having pain on the abdomen (lines 14-15). Using "any" the nurse designs the question to presuppose a no-problem, optimal situation (Boyd \& Heritage, 2006). The mother confirms this presupposition and the nurse asks the third question connecting it as an additional part of the same course of action with "entäs", "how about" (line 18). During this discussion, the nurse gets a lot of information about the mother's condition and based on this information, she normalizes the mother's symptoms and gives information about the causes of the normal symptoms (from line 24 onwards). 
The nurse's actions in Extracts 1 and 3 are in a similar sequential location. While in both, the nurse gazes at the mother, they differ in terms of turn design. In Extract 3, the nurse poses restricted follow-up questions that address some normal symptoms of pregnancy whereas in Extract 1, the nurse opens space for the mother to elaborate on her problem. Accordingly, in Extract 1 the mother elaborates on her condition bringing up numerous different aspects of it: the nausea started at Easter; it is worse than when she was expecting her firstborn; it is difficult to cope at home. Later (not shown in the transcript) she describes for example, her feelings of having kind of panic attacks and how it is difficult for her to have sick leave as she works in a family business. In Extract 3, on the other hand, the mother gives more details about the issues the nurse asks about. Compared to Extract 3, in Extract 1, the mother is given an opportunity to address those aspects of the problem she finds relevant and not only the ones the nurse asks about. In Extract 3, the nurse normalizes the mother's symptoms whereas in Extract 1, the nurse normalizes only some of the symptoms, gives several advice, and later during the encounter refers the mother to the doctor (not shown in the transcript). In sum, topicalizing by formulating and gaze encourages the mother to elaborate on the problem from her perspective and this helps the nurse to get information also about those issues that are not normal or typical problems during pregnancy.

\section{Topicalizing the problem by formulating and gaze after different types of problem}

\section{descriptions, and in different stages of dealing with the problem}

The nurse may formulate the parents' problem descriptions that range from being very explicit to very implicit and they may be responses to the nurse's initial inquiry, to a follow-up question or even to a solution. To further illustrate that the practice of topicalizing by formulating and gaze is not tied to a certain sequential place or the design or topic of the problem-indicative utterance, we present two more cases in which the nurse topicalizes the parents' problem in 
different stages of dealing with the problem and after both explicit and implicit problem-indicative utterances.

Extract 4 illustrates a case in which the nurse topicalizes an implicit problem description by the parents. At the beginning of the encounter, the father has reported that the five-month-old baby has been crying at night before going to sleep. The exact time of crying has not been addressed and the nurse has concluded that "fighting against sleep" or crying because of being overtired is typical of babies. After normalizing the problem this way, the nurse has continued to interview parents about other topics. Extract 4 begins some 15 minutes later, after the routine measurements of the baby. At the beginning of the extract, the nurse is writing down the baby's measurements. She has given some advice about feeding while writing. At line 1, the baby whimpers, which probably occasions the topic of the baby being more demanding, initiated by the nurse at lines $2-3$.

\section{Extract 4 (baby 5 months old)}

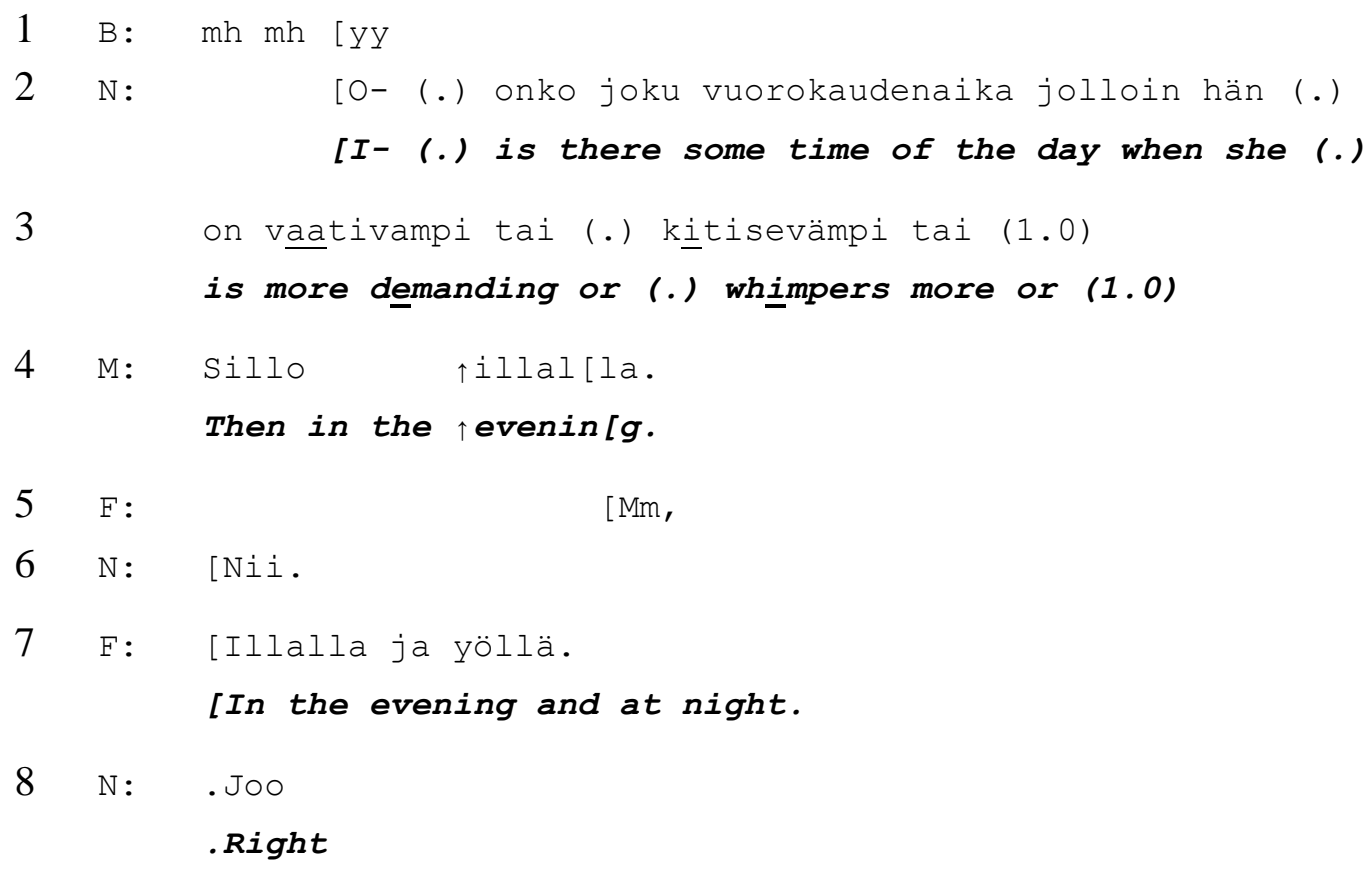




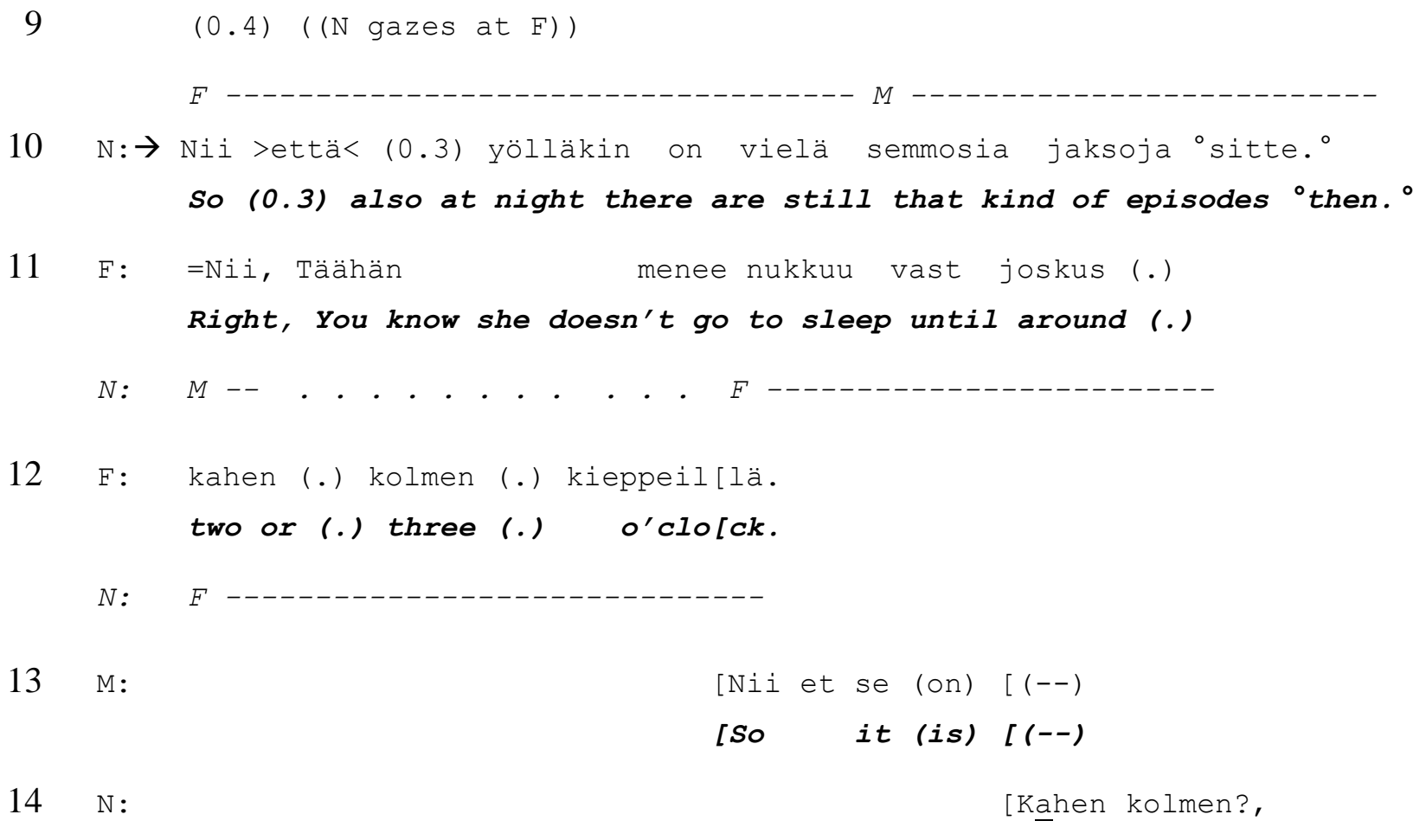

[Two or three?,

The design of the nurse's question presupposes that there may be a certain time of the day when the baby is more demanding. Although this topic is related to the discussion at the beginning of the encounter some 15 minutes earlier, the nurse's question is designed to open a new topic. The parents' answers implicitly describe a problematic situation as they confirm the candidate answer (Pomerantz, 1988) suggesting a problematic situation. Further, by choosing the particle "sillo", "then" the mother refers to the previous problem description at the beginning of the encounter by drawing a parallel between the situation described and the problem already mentioned.

The nurse first receives the mother's problem-indicative answers at line 6 with a particle "nii" which indicates that she recognizes the situation (Sorjonen, 2001, pp.164). The nurse further receives the father's answer with a response particle "joo", "right" (line 8) after which she remains quiet and continues to gaze at the father. The parents do not take the turn to elaborate on the problem. At line 10, the nurse formulates the parents' problem-indicative utterances and addresses the problem-relevant aspect "night" provided by the father. The clitic "-kin", translated as "also", connected to the word "night" marks that they have not yet talked about the nights, and the word "still" presents the situation 
as something that has continued. The nurse remains quiet after her formulation and gazes at the parents both at the closure of her formulation and at the first possible completion of the formulation-decision pair (once the father has confirmed the formulation at line 11), thus showing engagement in receiving more talk about the issue (Goodwin, 1981; Rossano, 2012; Ruusuvuori, 2001). As the formulation addresses the problem and the nurse orients to receiving more talk about the problem by remaining quiet and gazing at the parents, the parents get space to elaborate on the problem. Accordingly, the father continues to give details about the baby's rhythm at night and it turns out that she does not go to sleep until two or three o'clock. The nurse receives this as new information by repeating "two or three" with rising intonation (line 14). Although the parents' have said that the baby cries at night before going to sleep at the beginning of the encounter, the exact time of crying was not addressed. Thus, the same situation with the baby that was normalized at the beginning of the encounter is now oriented to as a problem that needs advice by the nurse: after a brief discussion about the problem the nurse advices that the baby's rhythm might be modified gradually by waking her up a bit earlier every morning (not shown in the transcript).

The following extract further demonstrates that formulating and gaze can topicalize both implicit and explicit problem descriptions. It also shows how the problem description can be topicalized both after the first problem-indicative utterance and after a further elaboration of it. The nurse's turns in focus are at lines 9 and 22-23.

\section{Extract 5 (baby 3 weeks old)}

1 N: Mites teil on muuten ny sitten men ny (.) arkielämä(h) ? .hh How has it been otherwise (.) in your everyday life now then? hh

$2 \quad(0.2)$

3 F: No?, $(0.6)$

Well?, (0.6) ((turns to gaze at M)) 


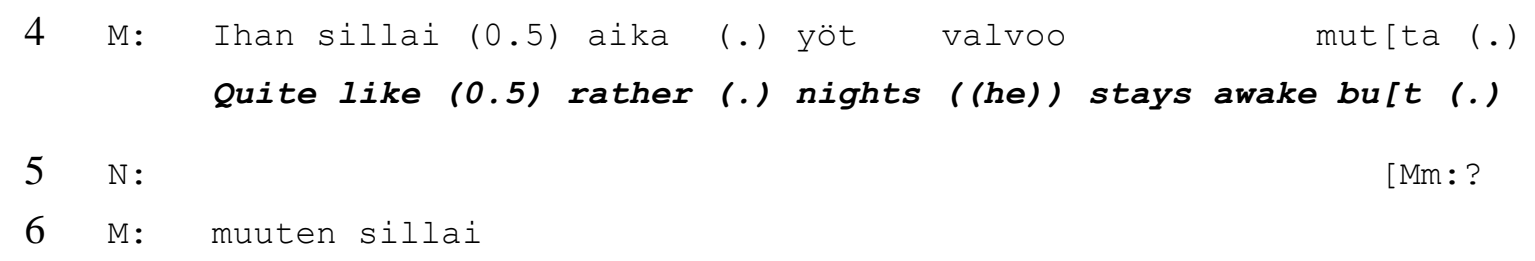

$13 \mathrm{~N}$ :

$(0.2)$

15 F: Välillä (.) s:aattaa olla semmosia öitä että (0.4) m (.) Sometimes (.) there might be the kind of nights when (0.4) $\mathrm{m}$ (.)

18 F: esimerkiks viime yönäki ni (0.4)

for example also last night (0.4) ((gazes at M))

19 M: Se nukku kahtee asti?, He slept until two o'clock?, 


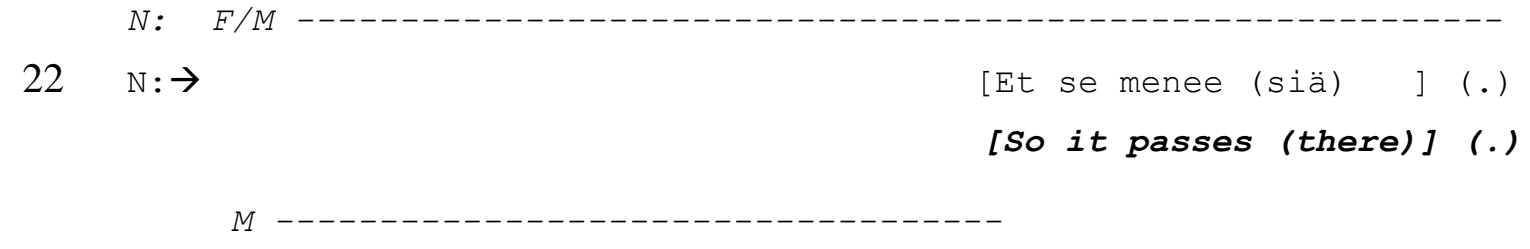

$23 \mathrm{~N}$ : aamuyö sitte ihan [valvoessa?

the small hours then just [being awake?

24 M:

[Joo, Se: nukalhtaa joskus s:eittemää.

[Yes, He: falls [asleep about at s:even.

$N:$

$M$

$25 \mathrm{~N}:$

[. J०O,

[. Yes,

$M---$

$26 \mathrm{~N}:$ Joo:?

Yes:?

27

(.)

$28 \mathrm{~N}$ : Joo, $[=£(-)$ he he hee£

Yes, $[=£(-)$ he he heef

29 M: [Tai sillai et se (0.4) niinku aika pitkiä aikoja valvoo

lor like he (0.4) you know stays awake quite long times

$N$ :

30 M: [(just sillai) ihan yliväsyny et se niinku .hhh nukahtaa

[((he is)) (just like) totally overtired so he you know .hhh falls

$31 \mathrm{~N}: \quad[\mathrm{J} \circ \mathrm{O}$,

[Yes,

32 M:

[ja sitte (.) herrää ja [(0.8) sillai et se ei

asleep [and then (.) ((he)) wakes up and [(0.8) like he doesn't

$33 \mathrm{~N}$ :

$[\mathrm{Mm}:$ ?

$\left[\mathrm{Mm} \mathrm{m}{ }^{\circ} \mathrm{m}^{\circ}\right.$,

34 M: (.) niinku (.) saa siitä unen päästä kiinni,

(.) you know (.) get to sleep,

$(0.5)$

$36 \mathrm{~N}$ : .h .mt Mites te ootte nyt sitte jaksanu ku te ootte ne yöt, .h .mt How have you ((plural)) survived those nights now when you

=ootteks te $(0.2)$ öisin vuorotellu vai $((\ldots))$

have, =Have you ((plural)) (0.2) taken turns at nights or $((\ldots))$ 
At line 1, the nurse poses an open question about the family's everyday life with a newborn baby. The mother's answer describes a problem in an implicit way. There are indications both of negative ("nights he stays awake") and positive ("fine") matters and the problem indication is due to the juxtaposition that the mother rebuilds in her answer: if the situation is "otherwise like fine" but the baby stays awake, this is depicted as problematic. The nurse offers an upshot formulation of the mother's implicit problem description and addresses the negative aspects of her utterance rather than the positive ones (line 9). The nurse also shortly joins the laughter initiated by the mother which demonstrates sensitivity to the delicacy of the topic. At the end of her formulation and after the mother's confirmation, the nurse gazes at the parents and this way displays engagement in receiving more talk about the topic (Goodwin, 1981; Rossano, 2012; Ruusuvuori, 2001). Thus, by addressing the problem-relevant aspects in her formulation, and gazing at the parents, the nurse makes relevant further elaboration of the problem. Both parents first confirm the formulation (the mother shortly at line 10 and the father with an upgrade at line 12) and then elaborate on the baby's rhythm (lines 15-21).

At lines $22-23$, we see the second formulation in this extract. So far, in all our examples the problem has been topicalized right after the parents' first problem-indicative utterance. Here the formulation comes after the parents have already elaborated on the problem. Again the formulation addresses the problem-relevant aspects instead of focusing on the occasional good nights (the parents tell that sometimes the baby wakes up only once) and the nurse gazes at the parents. Formulating and gaze make relevant even further elaboration of the problem and this is what the parents do (lines 24-34). At lines 36-37, the nurse asks a follow-up question that steers the conversation towards discussing about solutions for the problem and giving advice by the nurse. 
In sum, Extract 5 gives two examples of topicalizing by formulating and gaze. The first formulation topicalizes an implicit problem description which is the first problem-indicative utterance by the parents. The second formulation topicalizes an explicit problem description which elaborates the initial problem-indicative utterance.

The two preceding extracts have illustrated that topicalizing by formulating and gaze serves to open space for parents to elaborate on their problems after both explicit and implicit problemindicative utterances and in different stages of dealing with the problem. Thus, the practice is not tied to a particular design of the problem-indicative utterance or a particular stage of dealing with the problem, but it can be used in various contexts of dealing with problems in $\mathrm{MCH}$ clinics.

\section{Conclusions}

In this article we have presented a practice which nurses use to open space for parents to elaborate on their problems in Finnish preventive maternity and child health clinics. Two interactional features were demonstrated to be relevant for this practice: 1) the nurse addresses the parents' preceding problem-indicative turn by focusing on the problem-relevant (rather than benign or normal) aspects of it in her formulation of what they say, and 2) she orients to receiving more talk about the problem by leaving space and by gazing at the parents at the closure of her formulation and at the first possible completion of the formulation-decision pair. The practice was illustrated to work in the same way in different stages of dealing with the problem and after different types of problem-indicative utterances. We also showed how the practice of topicalizing by formulating and gaze differed from asking follow-up questions on the topic in managing the problem.

The interactional practice of formulating has been widely studied in institutional encounters, for example, in news interviews (Heritage, 1985), meetings talk (Barnes, 2007) and especially in 
counselling and therapy encounters (Antaki, 2008; Hutchby, 2005; Weiste \& Peräkylä, 2013). The association between formulations and topic talk was first pointed out by Heritage and Watson $(1979,1980)$, and it has been further demonstrated in several studies analysing formulations in different institutional settings. In news interviews, for instance, formulations are routinely oriented to as elaborations on the topic, "as alternatives to going on to a next question" (Heritage, 1985, pp. 115). In meetings talk, candidate pre-closing formulations typically include lexical and sequential properties that mark acceptance of contributions for the task in hand so far, thus indicating readiness to proceed (Barnes, 2007, pp. 283-285). In health care encounters, formulations have been suggested to both initiate topic shift (Beach \& Dixson, 2001) and occasion more talk on the topic (Hutchby, 2005). This article contributes to this previous knowledge on the function of formulating in preserving and closing topics. We have provided a detailed analysis of the practice of topicalizing by formulating and gaze which seems to have specific features in the context of dealing with problems in $\mathrm{MCH}$ clinics compared to the cases in which formulating is used to steer the conversation towards closing talk about the problem (as in Extract 2). These features include both the design of the formulation and the multimodal displaying of engagement in receiving more talk about the problem.

Based on his comparative analyses, Drew (2003, pp. 305-307) has suggested that formulations have different functions in various institutional settings, and are typically associated with the institution's core tasks. One core task in preventive health care settings is to encourage clients to talk about potential problems in order to address them at an early stage. Heritage and Sefi (1992, pp.380) illustrated that in health visitor-mother encounters the health visitor's focusing questions about the problem help to get a comprehensive picture of it and to shape the advice to the problem. We suggest that the practice of topicalizing by formulating and gaze may be seen as a particular instrument for encouraging parents to elaborate on their problem descriptions compared 
to other ways of posing focusing questions. As Extracts 1 and 3 illustrated, compared to the typical yes/no-questions largely used in $\mathrm{MCH}$ clinic encounters, formulating sets the parents' own experience more explicitly in the focus, as it returns the parents' own words to them to be confirmed and elaborated on. In our data from MCH clinics, parents commonly present their problems implicitly (as in Extracts 4 and 5), which presumably has to do with the basic orientation of preventive MCH towards a benign situation (Bredmar \& Linell, 1999). This method of presenting the problem in an implicit way comes close to the way in which telling about a problem is initiated in everyday conversations using "trouble-premonitory" responses (Jefferson, 1980, 1988). Thus, the action of dealing with the problem in MCH clinics is not only about solving the problem but also quite fundamentally about negotiating if the issue needs to be solved - if it is a problem or "business as usual” (Jefferson, 1980).

In primary care encounters, the patients need to justify the doctorability of their concern (Heritage, 2009) and in health visitor-mother encounters, the health visitors need to justify their visits to the mothers' homes (Heritage \& Sefi, 1992, pp. 412-413). Compared to these health care settings, preventive $\mathrm{MCH}$ clinics are unique as the encounters are routine and voluntary. However, as the institution also has a controlling function in society (Bredmar \& Linell, 1999; see also Heritage \& Lindström, 1998) talking about problems may be interpreted as undermining the parents' competence. Thus, the nurse has to strike a balance between talking about and solving problems and maintaining the trustful professional-client relationship which could be damaged if she questioned the client's capacities as a parent or suggested in some other way that the client had done something morally questionable. In this kind of a context, the implicit problem descriptions by parents offer an opportunity for the nurse to address them if she so chooses and the practice of topicalizing by formulating and gaze is one practice to do this. The practice is both sufficiently explicit to mark the issue as a problem and display that the nurse has been listening to the parents 
(see also Antaki, 2008, pp. 42; Hutchby, 2005), as well as being sufficiently implicit and neutral to enable the parents either to continue talking about the problem or not. Further, it enables the parents to talk about their problems and to maintain the image of a competent parent as they have the opportunity to decide what and how they focus on in their problem description. These results may be generalizable to other sequences of talking about problems in preventive health care settings as a possible way of topicalizing talk about problems (see Peräkylä, 2004).

In this article, we have also demonstrated the relevance of a fine-grained interplay between formulating and gaze, that is, their organization in continuing dealing with the problem. Our observations are in line with previous studies that have suggested the relevance of gaze direction and body posture for displaying orientation towards the on-going action (Goodwin, 1979, 1980, 1981; Heath, 1984; Mondada, 2006; Robinson, 1998; Robinson \& Stivers, 2001; Rossano, 2012, 2013; Ruusuvuori, 2001; Schegloff, 1998; Stivers \& Rossano, 2010). Previous studies on general practice encounters have shown that doctors and patients use gaze and body posture to communicate their preparedness to initiate the sequence of disclosing the reason for the visit (Robinson, 1998), coordinating the production of problem presentation (Ruusuvuori, 2001) and the transition from recording the history to examining the patient (Robinson \& Stivers, 2001). This study contributes to this previous knowledge on the importance of gaze direction in displaying engagement and organizing courses of action in health care settings by analysing the multimodal construction of one specific practice that is, topicalizing parents' problem descriptions. We suggest that it would pay to take the multimodal aspects into account in the effort to locate specific features of interactional practices in various settings in the future. 


\section{References}

Antaki, C. (2008). Formulations in psychotherapy. In A. Peräkylä, C. Antaki, S. Vehviläinen, \& I. Leudar (Eds.), Conversation analysis and psychotherapy (pp. 26-42). Cambridge: Cambridge University Press.

Antaki, C. (2012). Affiliative and disaffiliative candidate understandings. Discourse Studies, 14, $531-547$.

Barnes, R. (2007). Formulations and the facilitation of common agreement in meetings talk. Text \& Talk, 27, 273-296.

Beach, W. A., \& Dixson, C. N. (2001). Revealing moments: Formulating understandings of adverse experiences in a health appraisal interview. Social Science and Medicine, 52, 25-44.

Boyd, E., \& Heritage, J. (2006). Taking the history: questioning during comprehensive historytaking. In J. Heritage, \& D. W. Maynard (Eds.), Communication in medical care. Interaction between primary care physicians and patients (pp. 151-184). Cambridge: Cambridge University Press.

Bredmar, M., \& Linell, P. (1999). Reconfirming normality: The constitution of reassurance in talks between midwives and expectant mothers. In S. Sarangi, \& C. Roberts (Eds.), Talk, work and institutional order: Discourse in medical, mediation and management settings (pp. 237-270). Berlin / New York: Mouton de Gruyter.

Deppermann, A., \& Spranz-Fogasy, T. (2011). Doctors' questions as displays of understanding. Communication \& Medicine, 8, 111-122. 
Drew, P. (2003). Comparative analysis of talk-in-interaction in different institutional settings: A sketch. In P. J. Glenn, C. D. LeBaron, \& J. Mandelbaum (Eds.), Studies in language and social interaction: In honor of Robert Hopper (pp. 293-308). Mahwah, New Jersey: Lawrence Erlbaum.

Goodwin, C. (1979). The interactive construction of a sentence in natural conversation. In G. Psathas (Ed.), Everyday language: Studies in ethnomethodology (pp. 97-121). New York: Irvington Publishers.

Goodwin, C. (1980). Restarts, pauses, and the achievement of a state of mutual gaze at turnbeginning. Sociological Inquiry, 50, 272-302.

Goodwin, C. (1981). Conversational organization: Interaction between speakers and hearers. New York: Academic Press.

Heath, C. (1984). Talk and recipiency: Sequential organization in speech and body movement. In J. M. Atkinson, \& J. Heritage (Eds.), Structures of social action. Studies in conversation analysis (pp. 247-265). Cambridge: Cambridge University Press.

Heritage, J. (1985). Analyzing news interviews: Aspects of the production of talk for an overhearing audience. In T. A. van Dijk (Ed.), Handbook of discourse analysis, volume 3: Discourse and dialogue (pp. 95-117). London: Academic Press.

Heritage, J. (2009). Negotiating the legitimacy of medical problems: A multiphase concern for patients and physicians. In D. Brashers, \& D. Goldsmith (Eds.), Communicating to Manage Health and Illness (pp. 161-178). New York/London: Routledge. 
Heritage, J. (2010). Questioning in medicine. In A. F. Freed, \& S. Ehrlich (Eds.), "Why do you ask?" The function of questions in institutional discourse (pp. 42-68). Oxford: Oxford University Press.

Heritage, J., \& Lindström, A. (1998). Motherhood, medicine, and morality. Scenes from a medical encounter. Research on Language and Social Interaction, 31, 397-438.

Heritage, J., \& Sefi, S. (1992). Dilemmas of advice: Aspects of the delivery and reception of advice in interactions between health visitors and first-time mothers. In P. Drew, \& J. Heritage (Eds.), Talk at work: Interaction in institutional settings (pp. 359-417). Cambridge: Cambridge University Press.

Heritage, J. C., \& Watson, D. R. (1979). Formulations as conversational objects. In G. Psathas (Ed.), Everyday language. Studies in ethnomethodology (pp. 123-162). New York: Irvington Publishers.

Heritage, J. C., \& Watson, D. R. (1980). Aspects of the properties of formulations in natural conversations: Some instances analysed. Semiotica, 30, 245-262.

Hutchby, I. (2005). "Active listening": Formulations and the elicitation of feelings-talk in child counselling. Research on Language and Social Interaction, 38, 303-329.

Jefferson, G. (1980). On "trouble-premonitory" response to inquiry. Sociological Inquiry, 50, $153-185$.

Jefferson, G. (1984). On the organization of laughter in talk about troubles. In J. M. Atkinson, \& J. Heritage (Eds.), Structures of social action. Studies in conversation analysis (pp. 346-369). Cambridge: Cambridge University Press. 
Jefferson, G. (1988). On the sequential organization of troubles-talk in ordinary conversation. Social Problems, 35, 418-441.

Koivisto, A. (2011). Sanomattakin selvää? Ja, mutta ja että puheenvuodon lopussa. [Summary in English: Goes without saying? Finnish conjunctions ja, mutta and että in turn-final position]. <http://urn.fi/URN:ISBN:978-952-10-7323-6> Helsinki: University of Helsinki.

Koivisto, A. (2012). Discourse patterns for turn-final conjunctions. Journal of Pragmatics, 44, 1254-1272. Lerner, G. H. (2003). Selecting next speaker: The context-sensitive operation of a context-free organization. Language in Society, 32, 177-201.

Ministry of Social Affairs and Health (MSAH). (2004). Lastenneuvola lapsiperheiden tukena. Opas työntekijöille. [Summary in English: Child health clinics in support of families with children. A guide for staff]. Helsinki: Ministry of Social Affairs and Health.

Mondada, L. (2006). Participants' online analysis and multimodal practices: Projecting the end of the turn and the closing of the sequence. Discourse Studies, 8, 117-129.

Nishizaka, A. (2010). Self-initiated problem presentation in prenatal checkups: Its placement and construction. Research on Language and Social Interaction, 43, 283-313.

Peräkylä, A. (2004). Reliability and validity in research based on naturally occurring social interaction. In D. Silverman (Ed.), Qualitative research: Theory, method and practice (2nd ed., pp. 283-304). London: Sage.

Pomerantz, A. (1988). Offering a candidate answer: An information seeking strategy. Communication Monographs, 55, 360-373. 
Puura, K., Tamminen, T., Mäntymaa, M., Virta, E., Turunen, M.-M., \& Koivisto, A.-M. (2001). Lastenneuvolan terveydenhoitaja vauvaperheen tuen tarpeen havaitsijana [The child health nurse as a detector of the support needs of families with baby]. Suomen Lääkärilehti, 56, $4855-4861$.

Robinson, J. D. (1998). Getting down to business: Talk, gaze, and body orientation during openings of doctor-patient consultations. Human Communication Research, 25, 97-123.

Robinson, J. D., \& Stivers, T. (2001). Achieving activity transitions in physician-patient encounters: From history taking to physical examination. Human Communication Research, 27, 253-298.

Rossano, F. (2012). Gaze behavior in face-to-face interaction. Nijmegen: Radboud University Nijmegen.

Rossano, F. (2013). Gaze in conversation. In J. Sidnell, \& T. Stivers (Eds.), The handbook of conversation analysis (pp. 308-329). West Sussex: Wiley-Blackwell.

Ruusuvuori, J. (2001). Looking means listening: Coordinating displays of engagement in doctorpatient interaction. Social Science \& Medicine, 52, 1093-1108.

Ruusuvuori, J. (2005). "Empathy" and "sympathy" in action: Attending to patients' troubles in Finnish homeopathic and general practice consultations. Social Psychology Quarterly, 68, 204-222.

Sacks, H., Schegloff, E. A., \& Jefferson, G. (1974). A simplest systematics for the organization of turn-taking for conversation. Language, 50, 696-735.

Schegloff, E. A. (1998). Body torque. Social Research, 65, 535-596. 
Schegloff, E. A. (2007). Sequence organization in interaction: A primer in conversation analysis I. Cambridge: Cambridge University Press.

Sorjonen, M.-L. (2001). Responding in conversation: A study of response particles in Finnish. Amsterdam/Philadelphia: John Benjamins.

Stivers, T. (2007). Prescribing under pressure. Parent-physician conversations and antibiotics. Oxford: Oxford University Press.

Stivers, T., \& Rossano, F. (2010). Mobilizing response. Research on Language and Social Interaction, 43, 3-31.

Stivers, T., \& Sidnell, J. (2005). Introduction: Multimodal interaction. Semiotica, 156, 1-20.

Tiitinen, S., \& Ruusuvuori, J. (2012). Engaging parents through gaze: Speaker selection in threeparty interactions in maternity clinics. Patient Education and Counseling, 89, 38-43.

VISK = Hakulinen, A., Vilkuna, M., Korhonen, R., Koivisto, V., Heinonen, T. R., \& Alho, I. (2004). Iso suomen kielioppi. [Extensive Finnish grammar]. Helsinki: Suomalaisen Kirjallisuuden Seura. Online version, cited 11.1.2013. Available at: http://scripta.kotus.fi/visk.

Weiste, E., \& Peräkylä, A. (2013). A comparative conversation analytic study of formulations in psychoanalysis and cognitive psychotherapy. Research on Language and Social Interaction, 46, 299-321. 


\footnotetext{
${ }^{1}$ Two families with a child were video-recorded twice.

2 The following abbreviations are used to refer to participants in the extracts: $\mathrm{N}=$ nurse, $\mathrm{M}=$ mother, $\mathrm{F}=$ father and $\mathrm{B}=$ baby. The speaker's gaze direction is marked above the line in italics and the recipient's below. The lines (---) indicate continuous gaze direction. Quick shifts in gaze direction are indicated only by shifts in target, and slow shifts (head movements) with dots (...). (See Goodwin, 1981.)

${ }^{3}$ In Finnish, the particle "nii" can be used in various contexts in which it has different meanings. In some cases, it can be translated as "yeah"/ "yes". However, the particle can also be used as a response particle that marks affiliation (Sorjonen, 2001, pp. 164). As in these cases there is not an equivalent translation for the particle, it has been left without a translation and we explain the meaning in the text.
} 